December - 2016

\title{
Challenges of offering a MOOC from an LMIC
}

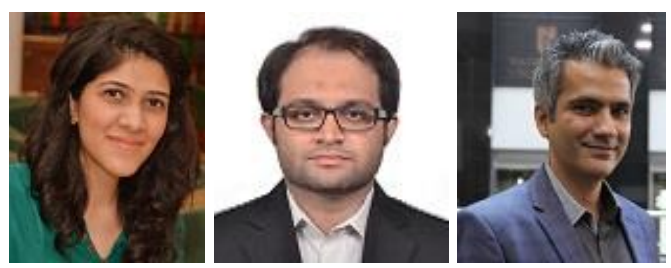

Aamna Pasha', Syed Hani Abidi2 ${ }^{2}$, and Syed Ali ${ }^{3}$

1, 2Aga Khan University, Pakistan, ${ }^{3}$ Nazarbayev University, Astana, Kazakhstan

\begin{abstract}
Massive open online courses (MOOCs) were initiated in the early 2000 s by certain leading American and European universities. An integral part of the MOOC philosophy has been to provide open access to online learning. Despite their potential advantages to local audiences, faculty and institutions, the number of MOOCs offered from low and middle income countries (LMICs) remains low. The intent of this paper is to provide a reflective perspective on a MOOC recently offered from an LMIC, namely, Pakistan. According to our analysis, the main concern for the organizers of this MOOC was to maintain a high standard of quality, and to offer a course topic that responded to the academic needs of this region. The pedagogical strategy also emphasized on allowing the participants flexibility of time, enabling them to access the course content despite limitations with power shortages, internet speeds, and computer literacy. Despite the lack of resources and expertise, there is significant enthusiasm to introduce this form of teaching and learning to LMIC audiences.
\end{abstract}

Keywords: MOOC, LMIC, Pakistan, distance learning

\section{Introduction}

A massive open online course (MOOC) refers to a course that has open and global enrollment, is fully online, and is free of cost (Esposito, 2012; St Clair, Winer, Finkelstein, Fuentes-Steeves, \& Wald, 2015; Suen, 2014). These courses are mostly non-degree and are currently being offered from leading institutions that are located predominantly in the west (Liyanagunawardena, Williams, \& Adams, 2013b; Suen, 2014). Interestingly, most of the MOOC participants also seem to be concentrated in the affluent English-speaking countries (Grossman, 2013; Liyanagunawardena, 2012; Liyanagunawardena, Williams, \& Adams, 2013a). Given the free access to quality content and instruction, such courses should have immense potential in developing countries (Castillo, Lee, Zahra, \& Wagner, 2015; Liyanagunawardena et al., 2013a). However, probably owing to technological constraints and the cost involved in overcoming them, there are less than a few institutions offering 
MOOCs from within low and middle income countries (LMIC). So far, LMICs that have previously offered MOOCs are India, China, Indonesia, and Malaysia (Wilson \& Gruzd, 2014). In 2014, Pakistan joined this small group of LMICs by offering its first MOOC from the platform of The Aga Khan University, Karachi. This paper examines the experience of developing the MOOC and the challenges faced by the course organizers

\section{Background}

Normally, MOOCs are offered completely online and are not delivered in real-time. Such courses, therefore, afford a great deal of flexibility to the participants in terms of space and time (Freitas, 2015; Sandeen, 2013). Adding further to their appeal, participating in MOOCs usually does not require a registration fee. Consequently, popularity of this learning method has rapidly increased over the years, with an over $100 \%$ increase in the number of courses offered in 2014 (Lewis, Comas-Quinn, \& Hauck, 2015). Elite universities are racing to partner with platforms such as Udacity and Coursera to offer MOOCS (Jordan, 2014), while technology giants, such as Google, are in the process of creating their own platform to assist in the building and hosting of MOOCs. While MOOCs offer several advantages to students, they also, on many levels, carry a great deal of appeal for teachers as well as for the patron institutions. The design and delivery of a MOOC gives the faculty an opportunity to reach a vast global audience and have greater recognition (Lewis et al., 2015). Although they may not generate considerable revenue, an institution may be interested in offering MOOCs to join the altruistic quest and dissemination of knowledge, and to earn a respectable standing in academia. At the same time, an institution may exploit this opportunity to innovate teaching methodology, and to showcase its faculty and programs (Das, Das, \& Das, 2015).

MOOCs have often been termed a disruptive innovation that has made higher education -an expensive, exclusive commodity- one that is accessible and affordable (Cooper, 2013). LMIC institutions can especially benefit from MOOCs since this form of teaching enables the institutions to reach out to a wider audience which, as in the case of many LMICs, may be scattered through rural and underprivileged settings. To such an audience, MOOCs would be especially appealing since this method of learning circumvents the costs involved in admission, travel, housing, etc. However, despite its obviously attractive benefits, the MOOC phenomenon still awaits its popularity surge in the LMICs. The number of the LMICs offering, and the LMIC participants attending, MOOCs continues to stay low (Liyanagunawardena et al., 2013b; Wilson \& Gruzd, 2014). One easily comprehensible reason may be the technical limitations, such as inaccessibility of the participants to an efficient computer or internet connection. For the institutions, such limitations may comprise inadequate technological provisions and expertise.

There are alternative narratives; however, on MOOCs being a phenomenon of the developed world that has the potential to intensify the influence of western academia (Altbach, 2014) and has limited scope in developing countries, both in terms of this format being used to offer courses and in its advantage to the masses. It is argued that the scope that does exist is for those who are already educated The challenges to MOOCs in developing countries continue to remain predominantly those of infrastructure, inclusion through language, evaluation, and accreditation(Castillo, Lee, Zahra, \& Wagner, 2015; Wildavsky, 2015). Some of the concerns aligned with MOOCs can be addressed and 
waived with greater MOOC offerings from LMIC institutions thereby adding voices to the narrative from local contexts. MOOC's potential in developing countries need to be identified and hurdles tackled for the innovation to have a greater impact and a wider acceptance.

\section{Research Design}

Although systematic analysis of published literature on MOOCs has highlighted the participant perspective, there is a dearth of information regarding the faculty perspectives on MOOCs (Liyanagunawardena, Williams, \& Adams, 2013a; Liyanagunawardena et al., 2013b). This paper attempts to patch this gap by offering a reflective analysis of the course organizers' perspective, and the challenges and concerns they had for the design and delivery of a MOOC from an LMIC. In this paper, using information gleaned from conversations with the course organizers and from direct observation of the course development process, we examine the experience of developing this MOOC from a pedagogical and technical point of view. Additionally, through interviews we probe into the course organizers' perspective in terms of the challenges they encountered when offering such a course in a format still relatively new to LMICs.

\section{MOOC from an LMIC}

Aga Khan University has one of its main campuses located in Karachi, Pakistan. The university is known for its dynamic approach towards education development and in the past has taken several initiatives in the area of online learning (Chauhan, Naseem, \& Rashwan, 2016).

In the year 2014, from the platform of Aga Khan University, Karachi campus, the first MOOC was launched from Pakistan. The course, Drug Discovery - A Computer Based Approach, aimed to introduce participants to the current concepts in computer-based drug design, allowed them to gain a hands-on experience of bioinformatics software and databases currently being employed in the area of Drug Discovery. The course was intended for Science undergraduate, graduate, and post-graduate students. The participants were required to have access to a computer with an internet connection and a commonly used browser. The course attracted 230 enrollments, including undergraduate, graduate, and post-graduate students, healthcare professionals, researchers, and university faculty, and ran for duration of three weeks, offering open enrolment with no participation fee. The teaching methodology included instructional and demonstrative videos, student-centered tasks, activities, and self-assessment quizzes. Publicity for the course was done by the Aga Khan University as well as by the instructors through email, flyers, and course pages on social media platforms. The course design and development was supported by a team of experts in the area of Blended and Digital Learning.. All but three participants who took the course survey were from Pakistan, with the remaining three residing in India, South Korea, and Mexico. Most survey participants were between 20-29 years of age, with almost twice as many female participants than male participants. Most MOOC participants who partook in the course survey listed their occupation as student, while some indicated that they were faculty members and/or researchers.

\section{Challenges and Concerns}


While developing the Drug Discovery MOOC, the major concern for the course organizers was the quality of content. There was a presentiment that the audience might underestimate the quality of the course content, and the expertise of instructors, since the MOOC originated from an LMIC. With regard to the content, course faculty felt participants might not think that someone teaching and undertaking research in this part of the world will be up to pace with the current trends and technology. On a larger level, the course organizers were also concerned about the quality of experience a participant would have from an LMIC-developed MOOC. In order to address these concerns, content was reviewed and vetted multiple times. The course development process was thoroughly monitored to ensure that the MOOC met the international standards. Additionally, to improve the participant's overall learning experience, special attention was paid to design a userfriendly and visually appealing course website.

The faculty's concern about the audience's misgivings regarding MOOCs from developing countries may offer a partial explanation for the reason why MOOCs are almost exclusively being developed by western universities. It is possible that institutions from LMICs have reservations about how warmly an LMIC MOOC would be welcomed by the audience worldwide. Of course, nonwestern countries are both underrepresented in academia and rank poorly on average citation score measures (Graham, 2011). Moreover, most of these universities are technologically ill-equipped compared to their western counterparts (Wildavsky, 2015).

Additionally, the course organizers mentioned that, given the course was developed from a platform that had not offered MOOCs in the past, it was a special consideration that the marketing for the Drug Discovery MOOC was done both widely and intensively. Traditionally, elite universities in the west have offered MOOCs on popular home or partner platforms, such as Udacity and Coursera, which are considerably well known; however, they too, have struggled with marketing. A US study reports that less than $25 \%$ of the general public had heard of MOOCs, and only $4 \%$ claimed to be very familiar with them (Grossman, 2013). Marketing will remain even a greater challenge for courses coming out of developing countries. These marketing strategies may need to be coupled with a plan to raise awareness of MOOCs in the LMICs.

\section{Pedagogical Considerations}

During the design of the course the organizers had a number of pedagogical considerations, particularly in the context of LMICs. Although the course aimed to target audience from around the world, there was an underlying assumption that most participants would be from developing countries. The topic for the MOOC itself was chosen after identifying a knowledge gap in that subject area among the students from this region. Based on their teaching and research experience, the course organizers decided to develop a MOOC in the bioinformatics of drug design - a subject area which they felt was generally lacking in the Biomedical Sciences masters and PhD program curricula.

Online course formats are said to provide students the opportunity to "Mastery Learning." This concept, originally conceived by Bloom in 1968 (Benjamin, Hastings, \& Madaus, 1971), encourages students to achieve mastery in one area before moving to the next. However, in traditional methods of teaching, course materials and concepts move at the same pace for all students. MOOCs have tried to overcome this shortcoming by including short teaching videos coupled with quizzes or activities participation in which is normally not time-bound, facilitating formative assessment of students at each critical learning step. This allows students to learn at their own pace and revisit concepts when 
needed (Glance, Forsey, \& Riley, 2013; Saadatdoost, Sim, Jafarkarimi, \& Mei Hee, 2015). This was one important pedagogical concern for the organizers of the Drug Discovery MOOC. Each course video, therefore, was planned to be around 10 minutes long and was coupled with a learning activity with no rigid deadlines for completion.

Although its content was especially tailored to cater the needs of students from an LMIC, the course was intended to carry wide appeal to students studying at the same level at most institutions around the world. With regard to activity choices, one of the course facilitators mentioned that for an audience from an LMIC, the course was designed using very simple activities. Online learning is a relatively new phenomenon in these regions, requiring a high degree of independent learning, to which local learners may not be fully accustomed.

Similar to the report published by the Higher Education Academy, UK, on the Pedagogy of MOOCs, this view held by course organizers speaks to the issue of MOOC pedagogy being a negotiated practice. That is, several social and material influences must converge when the instruction for a MOOC is being planned. These include disciplinary influences, learner's background, and expectations, as well as teacher's preferences (Bayne \& Ross, 2014; Doherty, Harbutt, \& Sharma, 2015).

\section{Technical Considerations}

With regard to technical limitations, LMICs struggle with issues of power shortage, weak internet connectivity, low internet coverage, and low computer literacy (Farid, Ahmad, Niaz, Arif, Shamshirband, \& Khattak, , 2015; Greene, Oswald, \& Pomerantz, 2015; Jordan, 2014; Marcial, Caballero, Rendal, \& Patrimonio, 2015; Zheng, Rosson, Shih, \& Carroll, 2015). Keeping these limitations in mind, the course was designed to be flexible so that the students could work through the content at their own pace and around the limitations in their settings. All the course videos were therefore downloadable, and students were allowed to complete the course activities, including the self-assessment quizzes, in their own time, without any deadlines imposed. This allowed the students enough time to access the course depending on the availability of electricity and internet connection in their settings, and on the level of their proficiency in computer skills.

Another important technical consideration was for the course website to be user-friendly, enabling ease of navigation. Usability is often related to quality and with regard to online learning tools, it refers to tools being easy to use in order to ensure there isn't a cognitive overload as a result of the effort and attention required in the mere use of the tool (Fini, 2009). Since the participants attending this MOOC were expected to both be new to online learning and to self-directed learning it was important to ensure that the website design was not technically challenging for the participants.

During course design, a particular technological challenge for the organizers was the media development. The course plan included extensive use of videos, tasks, and quizzes. Resources and expertise required to create these were not readily available, as in the case of many LMIC settings. According to the organizers, however, these limitations proved to be a blessing in disguise, urging them to think beyond boundaries. This facilitated a great deal of improvisation to explore novel utility of preexisting resources and expertise. For the organizers, the biggest outcome of the process was the confidence they gained in their creative capabilities. 


\section{Concluding Remarks}

It is important for there to be more global experimentation with MOOCs in order for the innovation to serve students more effectively and to level the academic playing field. Seemingly unsurmountable limitations of resources and expertise may make this a daunting task in an LMIC setting. However, the experience of the Drug Discovery MOOC organizers demonstrates that with a little creativity and sense of adventure developing a MOOC from an LMIC institution is not as difficult and can have the added advantage of inculcating a sense of confidence - both for the institution and the faculty offering the MOOC.

MOOCs are a low-cost, open access mode of learning that carries untapped advantages particularly for the participants, faculty, and institutions in LMICs. Stepping into this market will allow the LMICs to take part in, gain from, and, more importantly, give new directions to the evolution of the MOOC phenomenon.

\section{Acknowledgment}

For the contributions made towards design, delivery and execution of the MOOC, the authors would like to acknowledge all the organizers and facilitators, including, Greg Moran, Azra Naseem, Tashmim Khamis, Raheel Lakhani, Mahwish Anwar, and Shiraz Nasim.

\section{References}

Altbach, P.G. (2014) MOOCs as Neocolonialism: Who Controls Knowledge? International Higher Education, 75, 5-7.

Bayne, S., \& Ross, J. (2014). The pedagogy of the Massive Open Online Course (MOOC): The UK view [PDF file]. The Higher Education Academy. Retrieved from https://www.heacademy.ac.uk/resources/detail/elt/the pedagogy of the MOOC UK vie $\underline{\mathrm{w}}$

Benjamin, B. S. B., Hastings, J. T., \& Madaus, G. F. (1971). Handbook on formative and summative evaluation of student learning. New York: McGraw-Hill.

Castillo, N. M., Lee, J., Zahra, F. T., \& Wagner, D. A. (2015). MOOCs for development: Trends, challenges, and opportunities. Information Technologies \& International Development, 11(2), 35 .

Chauhan, S., Naseem, A., \& Rashwan, E. (2016). Developing a quality checklist for designing blended learning course content. International Journal of Information and Education Technology, 6(3), 224. 
Cooper, S. (2013). MOOCs: Disrupting the university or business as usual? Arena Journal(39/40), 182-202.

Das, A. K., Das, A., \& Das, S. (2015). Present status of Massive Open Online Course (MOOC) initiatives for Open Education Systems in India-An analytical study. Asian Journal of Multidisciplinary Studies, 3(7).

Doherty, I., Harbutt, D., \& Sharma, N. (2015). Designing and developing a MOOC. Medical Science Educator, 25(2), 177-181.

Esposito, A. (2012). Research ethics in emerging forms of online learning: Issues arising from a hypothetical study on a MOOC. Electronic Journal of e-Learning, 1O(3), 315-325.

Farid, S., Ahmad, R., Niaz, I. A., Arif, M., Shamshirband, S., \& Khattak, M. D. (2015). Identification and prioritization of critical issues for the promotion of e-learning in Pakistan. Computers in Human Behavior, 51(A), 161-171.

Fini, A. (2009). The technological dimension of a massive open online course: The case of the CCKo8 course tools. The International Review of Research in Open and Distributed Learning, 10(5).

Freitas, S. I., Morgan, J., \& Gibson, D. . (2015). Will MOOCs transform learning and teaching in higher education? Engagement and course retention in online learning provision. British Journal of Educational Technology, 46(3), 455-471.

Glance, D. G., Forsey, M., \& Riley, M. (2013). The pedagogical foundations of massive open online courses. First Monday, 18(5).

Graham, M., Hale, S. A., \& Stephens, M. (2011). Geographies of the world's knowledge. London, Convoco! Edition.

Greene, J. A., Oswald, C. A., \& Pomerantz, J. (2015). Predictors of retention and achievement in a Massive Open Online Course. American Educational Research Journal, 52, 925-955. doi:0002831215584621.

Grossman, S. (2013, June 26). Survey finds only limited public awareness of MOOCs [Blog Post]. Retrieved from http://chronicle.com/blogs/wiredcampus/survey-finds-only-limited-publicawareness-of-moocs/44549

Jordan, K. (2014). Initial trends in enrolment and completion of massive open online courses. The International Review of Research in Open and Distributed Learning, 15(1).

Lewis, T., Comas-Quinn, A., \& Hauck, M. (2015). Clustering, collaboration, and community: Sociality at work in a cMOOC. Researching Language Learner Interactions Online: From Social Media to MOOCs, 45.

Liyanagunawardena, T. R. (2012). Information communication technologies and distance education in Sri Lanka: A case study of two universities. (Unpublished doctoral dissertation), University of Reading, Reading, UK. 
Liyanagunawardena, T. R., Williams, S., \& Adams, A. (2013a). The impact and reach of MOOCs: A developing countries' perspective. eLearning Papers(33).

Liyanagunawardena, T. R., Williams, S., \& Adams, A. (2013b). MOOCs: A systematic study of the published literature 2008-2012. International Review of Learning in Open and Distance Education, 14(3), 202-227.

Marcial, D. E., Caballero, R. D. B., Rendal, J. B., \& Patrimonio, G. A. (2015). “I am offline”: Measuring barriers to open online learning in the philippines. Information Technologies and Learning Tools, 45(1), 28-41.

Saadatdoost, R., Sim, A. T. H., Jafarkarimi, H., \& Mei Hee, J. (2015). Exploring MOOC from education and information systems perspectives: A short literature review. Educational Review, 67(4), 505-518.

Sandeen, C. (2013). Integrating MOOCS into traditional higher education: The emerging "MOOC 3.0" era. Change: The Magazine of Higher Learning, 45(6), 34-39.

St Clair, R., Winer, L., Finkelstein, A., Fuentes-Steeves, A., \& Wald, S. (2015). Big hat and no cattle? The implications of MOOCs for the adult learning landscape. Canadian Journal for the Study of Adult Education, 27(3), 65-82.

Suen, H. K. (2014). Peer assessment for Massive Open Online Courses (MOOCs). The International Review of Research in Open and Distributed Learning, 15(3).

Wildavsky, B. (2015). MOOCs in the developing world: Hope or hype? International Higher Education, 8o, 23-25.

Wilson L., \& Gruzd A. (2014). MOOCs-international information and education phenomenon? . Bulletin of the American Society for Information Science and Technology, 4O(5), 35-40.

Zheng, S., Rosson, M. B., Shih, P. C., \& Carroll, J. M. (2015). Understanding student motivation, behaviors and perceptions in MOOCs. Paper presented at the Proceedings of the 18th ACM Conference on Computer Supported Cooperative Work \& Social Computing.

\section{Athabasca}

University

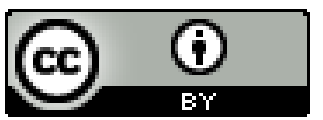

